See Article page 90.

\section{Commentary: In a disappointing outcome, much can be learned}

\author{
Karthik Thangappan, MD, and \\ David L. S. Morales, MD
}

The article by White and colleagues ${ }^{1}$ describes the management of a rare but significant complication during left ventricular assist device (LVAD) placement. Only a handful of pediatric septal hematoma cases have been reported since the first significant report by Drago and colleagues in 2005. ${ }^{2}$ This complication would more commonly be anticipated during ventricular septal defect repair procedures. It is specifically rare in the setting of LVAD placement.

A septal hematoma has rarely been described in LVAD placement and not in children. However, the occurrence of this complication is quite conceivable. Many of our pediatric patients have significant trabeculations, or noncompaction, that need to be excised to place a ventricular assist device, which could lead to bleeding into the septum. Also, the apical cannula is often quite large in respect to the ventricular cavity, which could cause trauma to the septum. The likelihood of these events occurring are innately greater when dealing with such a small heart. Whatever the mechanism of injury was, the most important factor is recognizing the injury quickly, as was done in this reported case. As seen in the representative figures and videos accompanying the article, intraoperative transesophageal echocardiography was used to visualize the hematoma and allowed the surgeons to

\footnotetext{
From the Department of Cardiovascular Surgery, Cincinnati Children's Hospital Medical Center, Cincinnati, Ohio.

Disclosures: Dr Morales discloses the following: consultant and instructor for Berlin Heart, Inc; proctor and consultant for Syncardia, Inc; national primary investigator for the 50/50cc Syncardia Total Artificial Heart Food and Drug Administration trial; consultant for Medtronic Inc (HeartWare Division); consultant for Abbott Medical Inc (Thoratec Division); and consultant, investigator, and member of medical advisory board for CorMatrix Cardiovascular, Inc. Dr Thangappan has nothing to disclose with regard to commercial support.

Received for publication Sept 28, 2019; revisions received Sept 28, 2019; accepted for publication Oct 28, 2019; available ahead of print Nov 6, 2019.

Address for reprints: Karthik Thangappan, MD, or David L. S. Morales, MD, Department of Cardiovascular Surgery, Cincinnati Children's Hospital Medical Center, 3333 Burnet Ave, MLC 2004, Cincinnati, OH 45229 (E-mail: Karthik. Thangappan@cchmc.org or David.Morales@cchmc.org).

JTCVS Techniques 2020;1:93-4

2666-2507

Copyright (c) 2019 The Author(s). Published by Elsevier Inc. on behalf of The American Association for Thoracic Surgery. This is an open access article under the CC BY-NC-ND license (http://creativecommons.org/licenses/by-nc-nd/4.0/).

https://doi.org/10.1016/j.xjtc.2019.10.002
}

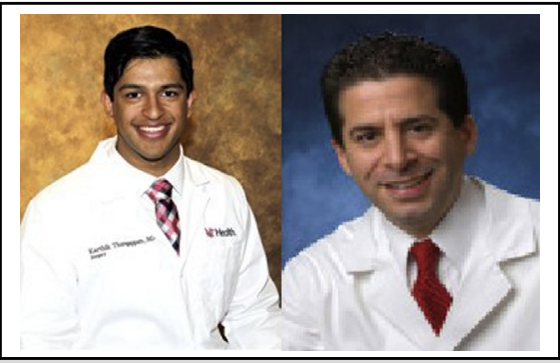

Karthik Thangappan, MD (left), and David L. S. Morales, MD (right)

CENTRAL MESSAGE

An expanding septal hematoma complicating LVAD placement warrants immediate action, and converting to a BiVAD via atrial cannulation would commonly be agreed upon as the next logical step.

change their mechanical circulatory support strategy during the same operation, thus immediately addressing the issue.

In response to the immediate sequelae of the septal hematoma including poor LVAD filling, ventricular fibrillation, diminished septal function, and hemodynamic instability, the patient was converted to biventricular support via bi-atrial cannulation. Although not necessarily innovative, this is the logical next step for a patient with a ventricular-placed LVAD that cannot fill. This situation is akin to trying to support a patient with small ventricular cavities (eg, restrictive cardiomyopathy) that cannot really accommodate an apical cannula. ${ }^{3}$ Most congenital heart surgeons would have pursued the same treatment algorithm in this scenario, but it is worth commending the surgical and anesthesia teams for recognizing the injury quickly and taking prompt action. Unfortunately, despite appropriate postoperative care and anticoagulation, due to multiple thromboembolic events, the patient did not survive. Although this case did not result in a positive outcome, the authors did manage to achieve success at least in supporting the patient through the hematoma complication. We applaud the authors for sharing their learnings even in a case resulting in death (something not done perhaps as often as our community should) because as we all know well, in a disappointing outcome, much can be learned. 


\section{References}

1. White BR, Savla JJ, Burstein DS, Mascio CE, O'Connor MJ, Szwast AL, et al. Interventricular septal hematoma complicating placement of a ventricular assist device in an infant and support with bi-atrial cannulation. J Thorac Cardiovasc Surg Tech. 2020;1:90-2.
2. Drago M, Butera G, Giamberti A, Lucente M, Frigiola A. Interventricular septal hematoma in ventricular septal defect patch closure. Ann Thorac Surg. 2005;79:1764-5.

3. Dykes JC, Reinhartz O, Almond CS, Yarlagadda V, Murray J, Rosenthal DN, et al. Alternative strategy for biventricular assist device in an infant with hypertrophic cardiomyopathy. Ann Thorac Surg. 2017;104:e185-6. 